\title{
Research on the Stratified Teaching Mode of Minority Preparatory Mathematics Courses
}

\author{
Zhifeng $\mathrm{Yu}^{1, \mathrm{a}}$ \\ College of Ethnic Education, Nanchang Institute of Science\& Technology, Nanchang, Jiangxi, \\ 330108, China \\ ayuzhifeng@126.com
}

Keywords: Minority preparatory courses; Mathematics courses; Stratified teaching; Research

\begin{abstract}
The mathematical basis of every minority preparatory student is uneven due to the existence of various differences. The "one-size-fits-all" teaching method used in the past can not meet the needs of quality education. However, the stratified teaching method is a teaching method for all students to follow the principle of teaching students in accordance with their aptitude. Based on the study of stratified teaching method in minority preparatory mathematics teaching, this paper analyzes the feasibility of its implementation in minority preparatory course, aiming to provide theoretical guidance for the majority of front-line educators.
\end{abstract}

\section{Introduction}

Starting from the reality of the minority areas, the minority preparatory education is a special form of higher education set up for the training of qualified college students in minority areas, is a teaching class system for students to lay a good foundation for their professional study in the colleges and universities, and is an important part of higher education in China. It is an urgent need for the rapid development of higher education in the new century to run a good minority preparatory education. In face of the specialities of science and technology which account for a large proportion of colleges and universities, it is particularly important to cultivate the mathematical basis of the preparatory students. Therefore, the Minority Department of Ministry of Education has taken the improvement of the results of mathematics, physics, and chemistry as the primary task of preparatory teaching. In order to further improve the math scores of the preparatory students, the author combines the characteristics of the minority preparatory students, adopts the stratified teaching method in the course of teaching, and forms a theoretical system by summarizing the experience of the teaching practice, hoping to play a guiding and inspiring role in the future minority preparatory science teaching.

\section{Implementation of Stratified Teaching}

Students Stratification. The object of the stratified teaching is the one-year preparatory Class 10 of Grade 2012. According to the results of the midterm and final exams of the first semester of this class, as well as the usual classroom performance and learning attitude, they are divided into three levels: A, B and C according to the proportion of 1:2:1. The A level is the top students, that is, they have a solid foundation in mathematics and can effectively master the content of teaching and complete the exercises and assignments, and in the hierarchical group, they can also help the students in B and C levels to solve the difficult problems. The B level is the middle level student. They have a good foundation of mathematics and can master most of the teaching content and complete the exercises and assignments with medium difficulty. In learning, they can ask questions to the A level students, and help $\mathrm{C}$ level students to solve simple problems. The $\mathrm{C}$ level is the backward students. Their mathematical basis is relatively weak, and they often have to do the exercises and assignments under the guidance of the teachers and the help of the A level and B level students.

After dividing the level, three different levels of students are assigned seats and each group is four people. In each group, there are one A level, two B levels and one C level, which is convenient 
for students at three levels to discuss, coach and communicate, and helps to improve together. There are 54 students in Class 12 of Grade 2012. Therefore, they are divided into 13 groups. Among them, there are 11 groups that there are 4 people in each group (one A level, two B levels and one C level), and 2 groups that there are 5 people in each group (one A level, three B levels and one C level). The students in A level in each group serve as the leader for the management of each group. The leader should be responsible for the study and homework between the group members. Teachers should regularly compare and assess the completion of the homework and the progress of the results of each group, so as to cultivate the team consciousness and competition consciousness among all groups, and create a strong learning atmosphere.

Teaching Objectives Stratification. Teachers should prepare lessons with different levels taking the "coordinating the whole and giving consideration to both ends" as the principle and according to the actual situation of students at different levels, and rationally formulate the teaching objectives for the students at various levels according to the knowledge structure of the textbook and the cognitive ability of the students. Teaching objectives generally follow these five steps from shallow to deep: (1)memorizing, (2)understanding, (3)simple application, (4)simple integrated application, and (5)complex integrated application. Different teaching requirements are adopted for students at different levels: The students in group A reach (1)-(5), The students in group B reach(1)-(4), and the students in group $\mathrm{C}$ reached (1)-(3).

For example, in the study of the "integration by substitution", the students in group C only need to use the integration by substitution of the first and second type to solve the simple integral type. The students in group B should be able to solve complex types, such as the general type of trigonometrical substitution and reciprocal substitution. The students in group A should be able to flexibly use two kinds of substitution methods to solve all kinds of integral types.

Classroom Teaching Stratification. Classroom teaching stratification is the most difficult and key link of stratified teaching. Teachers' classroom teaching should follow the principle of gradual improvement, from easy to difficult, and from simple to complex. Teachers should first let the C level basically understand, and then help the B level to solve the difficult point in time, and finally ensure that the A level does not wait while listening. At the same time, teachers should fully mobilize the enthusiasm of students, so that students at all levels have the opportunity to participate in classroom activities. They should also give the simple questions to the students in $\mathrm{C}$ level, give the moderate questions to the students in B level, and give the difficult questions to the students in A level. When the students have difficulty in answering the question, the teacher should give them proper guidance. For the students in B and C levels, teachers should have a deep understanding of their problems and difficulties, help them solve difficult problems, stimulate their spirit of active learning, and let them remain strong thirst for knowledge. For students in A level, students should be encouraged to think, explore, understand basic knowledge and basic methods in teaching, and generalize general rules and conclusions, and then the teachers should guide students to change problems, so as to help students to make the variable exploration. In addition, teachers should also arrange the teaching rhythm well, explain concisely and give students more chances to practice, and eliminate the cramming education and nonsense so as to save time to let students practice more.

Class Exercise Stratification. In classroom stratification teaching, class exercises should also be stratified. When preparing lessons, teachers should reorganize the exercises in textbooks or reselect and compile the exercises of different levels according to the reality of the students and the content of the teaching materials, and they also should design and arrange the classroom exercises according to the order from easy to difficult and from shallow to deep. When selecting and compiling three different levels of exercises, teachers must abide by the principle that the basic requirements are consistent and the principle that encourages the individual development. More generally, it is the "security at the end and no ceiling". Under the premise of ensuring that the basic requirements are consistent, the synthesis and skill of the exercises are divided into three levels.

Homework Stratification. After the end of the classroom stratification teaching, it is also necessary to assign different assignments to different levels to make students consolidate and improve their learning. In view of the different levels, the homework is generally assigned 
according to the following principles: The basic assignment should be assigned for the $\mathrm{C}$ level, which is mainly used to consolidate the basic definitions and methods. For the B level, it is based on the foundation, with a small number of questions with a slight increase in difficulty. The A level has half of the basic homework, and half of the questions with a certain degree of flexibility and comprehensiveness. The amount of homework should be moderate, and the students can complete within 20 to 30 minutes.

\section{The Advantages of Stratified Teaching}

The students of A level class are almost all top students. After years of study, they have developed a good habit of learning, corrected their learning attitude and had a better learning concept. Therefore, most of them can comply with school rules, and there is rarely a phenomenon that comes late and leaves early. At the same time, in class, they can be strict with themselves, and can listen carefully, take notes and interact with the teacher. Among them, liberal arts students are better than science students in these two aspects. Of course, there are also a few students coming late and leaving early. These very individual students are very incongruous in such a class. However, it is this kind of incongruity that makes these students gradually be assimilated by the vast majority of outstanding students after the teacher's proper admonition and instruction, and they also gradually begin to abide by discipline.

The students' interest in learning has been mobilized, and the students in class A all have the solid foundation. In daily teaching, teachers not only teach basic classroom knowledge, but also explain the variation of some typical examples and questions from shallow to deep. For these examples, either the method of solving the problem is unexpected, or it is easy to ignore the details, which greatly stimulates the students' exploration and curiosity. After they have mastered these methods and techniques, the sense of achievement arises, especially the science students. They will no longer feel that the course is not difficult and challenging. Letting them try the feeling of "jumping and picking a peach" can stimulate their interest in learning and mobilize their enthusiasm for learning to a great extent.

After solving basic questions, the students in B class can solve the questions with medium difficulty with little effort, so that the "zone of proximal development" of their thinking can be easily activated, which is conducive to their development of thinking.

The students in B class have a certain basis. Through their own efforts, they have the opportunity to get to the A level, which is a driving force for student learning. At the same time, they may also be transferred to $\mathrm{C}$ level due to their own slacking. This is also a kind of pressure. The drive of pressure and motivation makes most of the students in B level study harder.

The students in class $\mathrm{C}$ are relatively weak in foundation. However, through the increase of the teaching hours and the filling of basic knowledge, these students also gradually establish their interest and confidence in learning. Some students get to the B level through the hard work of one semester, and get a sense of achievement and improve the motivation of learning.

\section{Problems Encountered in Stratified Teaching}

How to Clearly Stratify and How to Divide the Scores in Each Level? At the beginning of the term, we carried out a placement test for this part of students. In order to meet the needs of teaching, according to the scores, we divided the classes and there are about 60 people in each class. The class whose students' scores are more than 80 is defined as class A, $60-80$ is defined as class B, and the score below 60 is defined as class $C$. However, the students with 75-80 points may have the ability of level A, and the students with 55-60 points may have the ability of level B. There are some problems in the stratification of students like this. In the future, we should consider how to clearly stratify.

The Students in the $\mathrm{C}$ Level are Weak in Foundation, Their Learning Autonomy is Poor and Their Self-Restraint Ability is Poor, and There is no Better Learning Atmosphere. The students in the $\mathrm{C}$ level are the key and difficult points in the teaching of stratified teaching. The 
teachers who teach students in the $\mathrm{C}$ level should have great patience and energy. They should unfailingly urge, remind and encourage students and correct their students' bad learning habits at all times. But there are still very few students with poor autonomy and poor self-discipline. They ignore the teaching of their teachers, and still go their own ways, which greatly frustrates the enthusiasm of teachers, and influences the learning atmosphere of the class. So the teaching for this part of the students is difficult.

The Stratification Disrupts the Original Natural Class Mode, and Makes the Collectivity and Cooperation Worse. The stratified teaching is a teaching class that is made up of several administrative classes. Therefore, the stratified class is also poor in collectivity and cooperation, which makes the teaching management of stratified classes more difficult and hinders the stratified teaching.

\section{The Effect of Stratified Teaching}

The stratified teaching is implemented after the end of the midterm examination of the second term for the students of one-year preparatory Class 10 of Grade 2012, in order to test the effect of the implementation of the stratified teaching method. The results of the midterm examination and final examination of the second term in the class are compared as follows.

\begin{tabular}{|l|c|c|c|c|c|}
\hline \multicolumn{1}{|c|}{ Table 1 } & The data comparison table of math scores in midterm and final exams \\
\hline Item & Total score & $\begin{array}{c}\text { Average } \\
\text { score }\end{array}$ & $\begin{array}{c}\text { Percent of } \\
\text { pass }\end{array}$ & $\begin{array}{c}\text { The highest } \\
\text { score }\end{array}$ & $\begin{array}{c}\text { The lowest } \\
\text { score }\end{array}$ \\
\hline $\begin{array}{c}\text { Midterm } \\
\text { exam score }\end{array}$ & 2596 & 48.1 & $30 \%$ & 92 & 9 \\
\hline $\begin{array}{c}\text { Final exam } \\
\text { score }\end{array}$ & 2856 & 52.9 & $32 \%$ & 93 & 29 \\
\hline
\end{tabular}

As can be seen from table 1, after implementing the stratified teaching method in this class, the pass rate of math scores has increased from $30 \%$ to $32 \%$, the average score has increased from 48.1 to 52.9, and the total score has also been improved. Therefore, the stratified teaching method is a practical teaching method in the mathematics teaching of the minority preparatory course.

Then the results are compared after the stratified teaching method is used at all levels.

\begin{tabular}{|c|c|c|c|c|c|c|}
\hline \multicolumn{2}{|c|}{ Table 2 The data comparison table of the math scores in midterm and final exams at } \\
all levels
\end{tabular}

As can be seen from table 2, the math scores at various levels have been improved after the use of the stratified teaching method. Among them, the scores of the students in the $\mathrm{C}$ level increase the most, and the average score increases by $20.5 \%$. The second is the students in B level, and the average score increases by $10.4 \%$. The last is the students in the A level. Their scores are only slightly improved, and the average score increases by 3.6\%. It can be seen that the stratified teaching method has the most significant effect on improving the academic performance of $\mathrm{C}$ level students, that is, it is the most useful for students with weak foundations to improve their math results. But for A level students, that is the top students, there is little effect. 


\section{The Suggestion of Stratified Teaching}

The first point is that the stratified teaching needs to consider the psychological quality of the students. The smooth development of stratified teaching needs to be controlled properly.

The second point is the lack of emotional communication between the stratified students. It is suggested that more extracurricular activities should be developed to promote the establishment of friendship in order to help each other and improve learning achievement.

The third point is to carry out the division of the effective levels according to the results, ability and interest of students.

The fourth point is to adopt an incentive mechanism to improve the enthusiasm of the students.

The fifth point is that teachers try to teach many levels at the same time, so that the differences between the levels can be clearly understood and the teaching reflection can be better done.

\section{Acknowledgements}

Science and technology research project of Nanchang Institute of Science\& Technology (GJKJ-16-27).

\section{References}

[1] X.R.Liu: Refining the Stratified Teaching and Creating a High Efficient Math Class[J], Popular Science(Scientific Education), 2012, 7.

[2] Z.Q.Wu, D.H.Zhao and B.Bai: Study on the Practice of Stratified Teaching[J], A Report from the Front Line of Education-The "11 th Five-Year" Excellent Educational Research Results of the Heilongjiang Institute of Education, 2011.

[3] S.Y.Zhang: Stratified Teaching-Teaching Students in Accordance with their Aptitude under Quality Education, The 11th Five-Year Stage Results Set of the National Teacher Scientific Research Fund (Shanxi Volume)[C], 2010.

[4] J.J.Zhu: Practice and Experience of Stratified Teaching[J], Examination Weekly Publishing, (2009)No.42.

[5] Y.P.Ying: Discussion on Stratified Teaching[J], Modern Chinese(Teaching Research Edition), 2006(9)

[6] P.Chen: A Brief Discussion on "Hierarchical Teaching" of High School Mathematics[J], Cutting Edge Education, 2010(8)

[7] S.Q.Zhang: A Brief Discussion on how to Carry on the Hierarchical Teaching[J], Quality Education(Teacher Education), 2011(10) 